up to $50 \% 5$-year survival has been reported. ${ }^{3,14}$ Thus involvement of the anterior abdominal wall does not necessarily mean that these lesions are

\section{References}

1. Mair, W.S., McAdam, W.A.F., Less, P.W.R., Jepson, K. \& Goligher, J.C. Carcinoma of the large bowel presenting as a subcutaneous abscess of the thigh. A report of four cases. Br J Surg 1977, 64: 205-209.

2. Feldman, M.A., Cotton, R.E. \& Gray, W.M. Carcinoma of the colon presenting as left perinephric abscess. Br J Surg 1969, 55: 21-26.

3. White, A.F., Haskin, B.J., Jenkins, C.K. \& Pfister, R.C. Abscess of the abdominal wall as the presenting sign in carcinoma of the colon. Cancer 1973, 32: 142-146.

4. Shucksmith, H.S. Subcutaneous abscess as the first evidence of carcinoma of the colon. Br J Surg 1963, 50: 514-515.

5. Krasheninnikoff, M. \& Duss, B.R. Mediastinal and subcutaneous emphysema caused by perforating sigmoid cancer. Acta Chir Scand 1988, 154(9): 541-542.

6. Merrill, J.G., Dockerty, M.B. \& Waugh, J.M. Carcinoma of the colon perforating onto the anterior abdominal wall. Surgery 1950, 28: 662-671.

7. Miller, L.D., Boruchow, I.B. \& Fitts, W.T. An analysis of 283 patients with perforative carcinoma of the colon. Surg Gynecol Obstet 1986, 123: 1212-1218. non-resectable. They are potentially curable lesions气 in spite of their size and wide excision of allz involved structures is recommended where feasible. $\stackrel{\mathbb{2}}{\circ}$

8. Welch, J.P. \& Donaldson, G.A. Perforative carcinoma of the $\frac{\bar{\sigma}}{\bar{c}}$ colon and rectum. Ann Surg 1974, 180: 734-740.

9. Stainland, J.R., Ditchburn, J. \& Dombal, F.T. Clinical ${ }^{\mathbb{\Phi}}$ presentation of disease of the large bowel. A detailed study of 642 patients. Gastroenterology 1967, 70: 22-28.

10. Dietz, M.W. A typical onset of colon cancer. Mo Med 1965, $\vec{\circ}$ 62: $448-458$.

11. Thurnam. Medullary fungus and ulceration of the transverse $\overrightarrow{\vec{\omega}}$ arch of the colon, with faecal abscess and fistulae. Trans Path Soc Lond 1846-8, 1: 265-266.

12. Goodman, P. \& Raval, B. CT of the abdominal wall. $A J R$ 1990, 154: 1207-1211.

13. Freeman, P.H., Oluwole, F.S. \& Ganepola, G.A.P. Unusual presentations of carcinoma of the right colon. Cancer 1979, 44: $1533-1537$.

14. Spratt, J.S. Jr \& Spjut, H.J. Prevalence and prognosis of $\vec{\sigma}$ individual clinical and pathological variables associated with colorectal carcinoma. Cancer 1967, 20: 1976-1985.

15. Astler, V.B. \& Collier, F.A. The prognostic significance of 0 direct extension of carcinoma of the colon and rectum. Ann Surg 1954, 139: 846-852.

\title{
A case of Churg-Strauss vasculitis complicated by small bowel necrosis
}

\author{
G.N. Schoretsanitis, D.M. Wakely, T. Maddox and C. Wastell \\ Academic Surgical Unit, Chelsea \& Westminster Hospital, 369 Fulham Road, London SW10 9NH, UK
}

Summary: A case of Churg-Strauss syndrome causing mesenteric intestinal ischaemia and small bowel necrosis is decribed in a 29 -year-old man. Despite conservative management, the patient's condition deteriorated and he underwent five laparotomies. Small and medium-sized arteries within the mesentery and lymph nodes showed necrotizing vasculitis. Currently he is doing well on oral nutrition and medical management.

\section{Introduction}

Acute intestinal ischaemia is a surgical emergency with life-threatening features. Mesenteric vasculitis is a rare cause of intestinal ischaemia accounting for $2 \%$ of cases. $^{1}$ Rheumatoid arthritis, scleroderma, systemic lupus erythematosus, giant cell arteritis, Wegener's granulomatosis and

Correspondence: Professor C. Wastell, M.S., F.R.C.S. Accepted: 22 February 1993
Churg-Strauss syndrome are systemic diseases $N_{0}$ which may rarely cause intestinal ischaemia and $N$ infarction. We describe a patient with Churg- N Strauss syndome who survived after multiple resections for small bowel necrosis.

\section{Case report}

A 29-year-old man with a 5-year history of bronchial asthma and allergic rhinitis was admitted to 
Westminster Hospital in June 1992 because of retrosternal pain radiating to the left arm, and epigastric pain associated with nausea. There was no family history of asthma or other atopic diseases.

Physical examination on admission revealed a mild pyrexia of $37.5^{\circ} \mathrm{C}$ and wheezes throughout both lungs. His abdomen was soft without palpable masses but very tender in the epigastrium. Laboratory examinations showed a white blood cell count of $32.8 \times 10^{9} / 1$ with a predominant eosinophilia $(66.5 \%)$ and the erythrocyte sedimentation rate was $86 \mathrm{~mm} /$ hour, other haematological parameters were unremarkable. Routine electrolytes were within normal limits, while alkaline phosphatase was elevated at $434 \mathrm{U} / 1$. IgA was $5.3 \mathrm{~g} / \mathrm{l}$ (normal $0.8-4.0$ ), IgE was $907 \mathrm{U} / \mathrm{ml}$ (normal $<81$ ), C-reactive protein $68 \mathrm{mg} / \mathrm{l}$ (normal $<10.0$ ). Anti-nuclear, anti-mitochondrial, antismooth muscle, anti-parietal cell, anti-reticulin and anti-neutrophil cytoplasm antibodies were all negative but rheumatoid arthritis (Latex) test was positive $(2 / 1,280)$. Bone marrow biopsy showed a reactive marrow with an increase in the eosinophilic compartment. Maturation was normal and there was no evidence of a leukaemia process. An initial chest X-ray was unremarkable. However, the electrocardiogram showed possible acute anterior infarction. Abdominal ultrasound was negative but computed tomographic scan showed some small left-sided para-aortic nodes. Upper gastrointestinal endoscopy, and biopsies of stomach and duodenum were all within normal limits, and liver biopsy showed an increased number of eosinophils.

The patient remained on the ward for 20 days, during which he received intravenous fluids, bronchodilators and ranitidine. His chest pain resolved, but the abdominal pain became steadily worse, the white blood cell count raised to $45 \times 10^{9} / 1$ and C-reactive protein to $462 \mathrm{mg} / 1$ (normal $<10.0)$.

At this stage (20 days post-admission). Churg-Strauss syndrome was suspected and the patient received an intravenous bolus dose of $1 \mathrm{~g}$ of cyclophosphamide with $1 \mathrm{~g}$ of methylprednisolone. The same dose of corticosteroid was repeated on the two following days. As his abdominal pain had not resolved, a laparoscopy was performed under general anaesthesia which showed diffuse peritonitis with extensive areas of small bowel necrosis. Laparatomy confirmed the above findings and a good major vessel blood supply to the small bowel was noted. It was clear that resection of a major portion, certainly more than $70 \%$, of the small bowel would be necessary. It was therefore decided, since arteries and veins right up to the small bowel itself were functioning well, that the entire small bowel would be returned to the peritoneal cavity in order to see if these areas of questionable viability would improve with steroid treatment. A policy of repeated laparotomies was formulated, the timing of which would be determined by the patient's progress, with particular reference to sepsis. Biopsies were taken from the small bowel and mesenteric lymph nodes.

The second laparotomy 2 days later required a conservative small bowel resection of $30 \mathrm{~cm}$ of jejenum and $30 \mathrm{~cm}$ of ileum which was irrevocably gangrenous. In addition the residual small bowel had numerous patches of necrosis some of which were locally excised.

Small intestinal biopsy showed focal mucosal ulceration with vasculitis affecting medium and small arteries in the mesentery and submucosa; adjacent veins were not involved (Figure 1). Within the walls and in the adjacent connective tissue, there was a dense, eosinophilic infiltrate extending into the muscularis propria and serosa. The lymph nodes also showed evidence of vasculitis and there was a prominent sinus histiocytosis and a mild oleogranulomatous reaction.

The third laparotomy was performed on day 3 and a further resection was required leaving $10 \mathrm{~cm}$ of jejunum and $80 \mathrm{~cm}$ of ileum. The fourth laparotomy was carried out on day 6 as perforation was suspected clinically. This proved not to be the case but four small ischaemic plaques were excised.

Specimens showed similar features to the original biopsy, except that they were more florid; the ulceration was more severe and the vessels more extensively necrotic. Infectious agents had been sought by special staining techniques; there was no evidence of helminthic infections, Treponema pallidum, Gram-positive or -negative organisms, cytomegalovirus, hepatitis surface antigen or any other pathogen.

In the time between laparotomies, the patient remained in the intensive care unit receiving total parenteral nutrition and antibiotics. Ten days after he returned to the ward he underwent a fifth

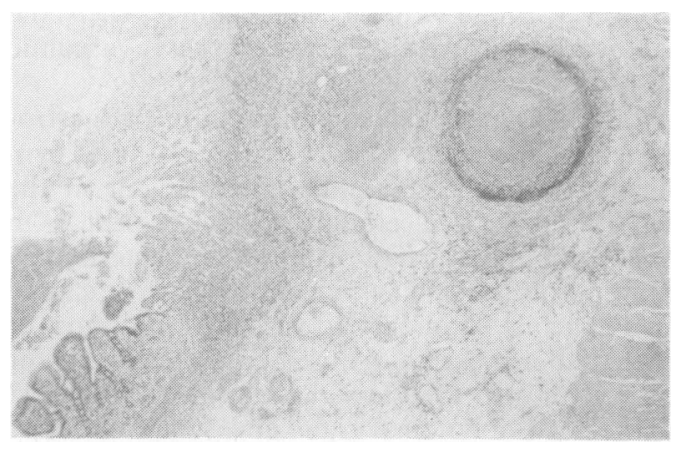

Figure 1 Mucosal ulcer with underlying inflamed and thrombosed artery. Note adjacent uninvolved vein $(\mathbf{H} \&$ $\mathrm{E}, \times 25)$. 
laparotomy for a large intraperitoneal abscess, which was drained. His postoperative course was largely uneventful after this and he started taking oral fluids and low residue diet. At that time, a month after the first, he received a second bolus of cyclophosphamide $(750 \mathrm{mg}$ ) and $15 \mathrm{mg}$ of oral prednisolone. $\mathrm{He}$ is currently well, his C-reactive protein, white blood cells and eosinophils are now within normal limits.

\section{Discussion}

Intestinal vasculitis is an uncommon cause of small bowel ischaemia and necrosis. ${ }^{1}$ Rheumatoid arthritis, ${ }^{2}$ scleroderma, ${ }^{3}$ polyarteritis nodosa, ${ }^{4-6}$ systemic lupus erythematosus, ${ }^{7}$ giant-cell arteritis, ${ }^{8-9}$ Wegener's granulomatosis and Churg-Strauss syndrome $e^{10,11}$ are a group of disorders which share inflammatory and necrotic features of blood vessels, and may involve the mesenteric circulation.

Allergic granulomatosis and angiitis (or Churg-Strauss syndrome ${ }^{11}$ ) is a rare disease of unknown cause. The syndrome is characterized by hypereosinophilia of both blood and tissues, and a systemic vasculitis in patients with allergic asthma or rhinitis. Although the classical lesion described by Churg and Strauss is the 'allergic granuloma', its absence does not exclude the diagnosis. ${ }^{12,13}$ The complete description of the clinical features and course of the disease has been reported by Lanham and co-workers. ${ }^{12}$ The differential diagnosis of vasculitis is very difficult and many patients have been described as having vasculitis of unknown cause. ${ }^{3,14}$ In addition many authors ${ }^{6,12}$ feel there is a close relationship between Churg-Strauss syndrome and many other granulomatous, vasculitic and eosinophilic disorders, and Churg-Strauss syndrome is considered as a point of overlap between these three disease spectra. The American College of Rheumatology ${ }^{15}$ developed criteria for the classification of Churg-Strauss syndrome. However, these criteria will change when the aetiology and pathogenesis of these vasculitic disorders are better understood.

In the English language literature, the gastrointestinal manifestations of Churg-Strauss syndrome include eosinophilic enteritis, but in the majority mucosa ulceration was not present. ${ }^{16} \mathrm{On}$ the other hand, Japanese cases are characterized by multiple ulcers which were considered to be caused by ischaemia secondary to vasculitis, but most of them had not been diagnosed until laparotomy or autopsy. ${ }^{17,18}$ In a large series of 165 patients, ${ }^{6} 52$ $(31 \%)$ had abdominal signs and symptoms. The most severe episodes of abdominal pain were due to peritonitis (nine cases), duodenal ulcer (three cases), intestinal infarction (one case) or unex- plained pain (one case), and 11 patients presented with gastrointestinal haemorrhage. However, these patients had systemic vasculitis of the polyarteritis nodosa (PAN) type and Churg-Strauss angiitis as described in Fauci's classification. ${ }^{19}$ The authors did not separate the two conditions because they believe these two forms of angiitis belong to the 0 same group. This theory has also been supported $\frac{\bar{O}}{\sigma}$ by other workers. ${ }^{12,20}$

In another series of 106 patients ${ }^{21}$ with vasculitis of various causes, 38 patients $(36 \%)$ had gastrointestinal manifestations. However, intestinal ${ }^{\infty}$ infarction was found in only three out of $13 \vec{\circ}$ patients with polyarteritis nodosum, and none with $\overrightarrow{\vec{\omega}}$ leucocytoclastic vasculitis.

A third series, reported by Camilleri et al., ${ }^{22} 18{ }_{0}$ out of 65 patients with systemic vasculitis had 3 . gastrointestinal involvement including abdominal ${ }^{2}$ pain $(85 \%)$, diarrhoea $(50 \%)$, and gut haemorrhage $(44 \%)$. This was confirmed histologically in $\frac{\sigma}{\sigma}$ 11 patients by finding non-specific inflammation $\infty$ (nine patients) and ulceration (two patients). $\quad \mathbb{\infty}_{\infty}$

Our patient had the typical features of $\frac{}{3}$ Churg-Strauss syndrome, including allergic rhinitis, history of bronchial asthma, eosinophilia, $\bigcirc$ systemic vasculitis and raised concentrations of $\frac{?}{0}$ IgE. It is interesting that all the IgE values in one series ${ }^{15}$ were elevated. This elevation supports the theory that an allergic mechanism is always presem $\&$ in this syndrome.

Should a patient present with abdominal sig표용 due to vasculitis, initial treatment with cyclophosphamide could possibly prevent the mesenteric ischaemia, as mesenteric vasculitis is associated $\precsim$ with a poor prognosis. ${ }^{6}$ Bacon and co-workers $\stackrel{\AA}{\AA}$ reported a decrease in both mortality and relapse $\overrightarrow{\overrightarrow{0}}$ rate in more than 100 cases of systemic necrotizing $\frac{3}{3}$ vasculitis using intermittent pulsed intravenous cyclophosphamide therapy. ${ }^{2,3}$ Intravenous combination of cyclophosphamide and methylprednisolone has also been proved very effective in 3 . patients with systemic vasculitis. ${ }^{24}$ In a prospective $\bar{\sigma}$ randomized trial of 71 patients ${ }^{25}$ the addition of cyclophosphamide to a regime of corticosteroids $\delta$ and plasma exchange has shown a reduction in the $₹$ incidence of relapses, in patients with polyarteritis 을 nodosum and Churg-Strauss vasculitis, without $\supset$ affecting the 10-year survival rate. However, it is felt this should be confirmed with a multicentre controlled prospective trial. ${ }^{26}$

Our patient received his first course of cyclo- $N$ phosphamide and prednisolone 20 days after the $\mathbb{\omega}^{N}$ onset of his abdominal symptoms, and a secondo course after his last laparotomy. From a surgicako point of view this patient retained the maximum ${ }_{\mathbb{D}}^{\complement}$ length of small bowel that was conceivably possi- $+\frac{\infty}{+}$ ble. The policy of repeated laparotomy, though 0 tedious, time consuming, expensive and hazardous

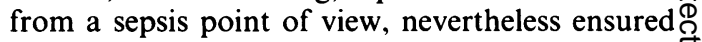


that any bowel capable of recovery was preserved. The problem with small bowel vasculitis is that the ischaemic process does not always affect the full thickness of the bowel. The mucosa may be lost with survival of the muscle and the lamina propria. In this situation mucosa can regenerate and the bowel be preserved. We are convinced that this policy was responsible for the small bowel preservation. Small bowel ischaemia or necrosis due to Churg-Strauss syndrome is a rare condition that requires prompt medical treatment and surgical intervention, if necessary.

\section{References}

1. Mosley, J.G. \& Marston, A. In: Marston, A., Buckley, G.B., Fiddian-Green, R.G. \& Hagland, U.H. (eds) Splanchnic Ischaemia and Multiple Organ Failure. Edward Arnold, London, 1989, p. 282.

2. Vollerstsen, R.S., Conn, D.L., Ballard, D.J., Ilsrup, D.H., Kaymar, R.C. \& Silverfield, J.C. Rheumatoid vasculitis survival and associated risk factors. Medicine 1986, 65: 365-375.

3. Clavlen, P.A., Muller, C. \& Harder, F. Treatment of mesenteric infarction. Br J Surg 1987, 75: 500-503.

4. Singh, R.P., Shah, R.C. \& Lee, J.T. Acute mesenteric vascular occlusion. Surgery 1975, 78: 613-617.

5. Scott, J.R., Miller, W.T., Urson, M. \& Stadalnick, R.C. Acute mesenteric infarction. Am J Roentgenol 1971, 113: 269-279.

6. Guillevin, L., Huong, D.LT., Godern, P., Jais, P. \& Wechsler, B. Clinical findings and prognosis of polyarteritis nodosa and Churg-Strauss angiitis: a study of 165 patients. $\mathrm{Br} J$ Rheum 1988, 27: 258-264.

7. Salisbury, R.S. \& Hazleman, B.L. Successful treatment of dissecting aortic aneurysm due to giant cell arteritis. Ann Rheum Dis 1981, 40: 507-508.

8. Smith, J.A.E., O'Sullivan, M., Gough, J. \& Williams, B.D. Small-intestinal perforation secondary to localized giant-cell arteritis of the mesenteric vessels. Br J Rheum 1988, 27: $236-238$.

9. Ljungstrom, K.G., Straudberg, V. \& Sandstedt, B. Infarction of the small bowel caused by giant cell arteritis. Acta Chir Scand 1989, 155: 361-363.

10. Specks, V. \& DeRemee, R.A. Granulomatous vasculitis: Wegener's granulomatosis and Churg-Strauss syndrome. Rheum Dis North Am 1990, 16: 377-397.

11. Churg, J. \& Strauss, L. Allergic granulomatosis, allergic angiitis and periarteritis nodosa. Am J Pathol 1951, 27: 277-301.

12. Lanham, J.C., Elkon, K.B., Pusey, C.D. \& Hughes, G.R Systemic vasculitis with asthma and eosinophilia: a clinical approach to the Churg-Strauss syndrome. Medicine (Baltimore) 1984, 63: 65-81.

13. Chumbley, L.C., Harrison, E.G. \& DeRemee, R.A. Allergic granulomatosis and angiitis (Churg-Strauss syndrome). Mayo Clin Proc 1977, 52: 477-484.

14. Ottinger, L.W. \& Austen, W.G. A study of 136 patients with mesenteric infarction. Surg Gynecol Obstet 1967, 124: $251-256$.
15. Masi, A.T., Hunder, G.G., Lie, J.T. et al. The American College of Rheumatology criteria for the classification of Churg-Strauss syndrome (allergic granulomatosis and angiitis). Arthritis Rheum 1990, 33: 1094-1100.

16. Walia, H.S., Abraham, T.K. \& Walia, H.K. Eosinophilic enteritis with perforation. Can J Surg 1988, 31: 268-269.

17. Shimamoto, C., Hirata, I., Dhshiba, S., Fujiwara S. \& Nishio, M. Churg-Strauss syndrome (allergic granulomatous angiitis) with peculiar multiple colonic ulcers. Am J Gastroenterol 1990, 85: 316-319.

18. Sasaki, A., Hasegawa, M., Nakazato, Y., Ishida, Y.\& Saiton, S. Allergic granulomatosis and angiitis (Churg-Strauss syndrome). Report of an autopsy case in a non-asthmatic patient. Acta Pathol Jap 1988, 38: 761-768.

19. Fauci, A.S. Vasculitis. J Allergy Clin Immunol 1983, 73: 211-233.

20. Finan, M.C. \& Winkelmann, R.K. The cutaneous extravascular necrotizing granuloma (Churg-Strauss granuloma) and systemic disease: review of 27 cases. Medicine 1983, 62 . $142-158$.

21. Lopez, L.R., Schocket, A.L., Standford, R.E., Claman, H.N \& Kohler, P.F. Gastro-intestinal involvement in leucocytoclastic vasculitis and polyarteritis nodosa. $J$ Rheumatol 1980 , 7: 677-684.

22. Camilleri, M., Pusey, C.D., Chadwick, V.S. \& Rees, A.J. Gastro-intestinal manifestations of systemic vasculitis. $Q J$ Med 1983, 52: 141-149.

23. Bacon, P.A., Vasculitis - clinical aspects and therapy. Acra Med Scand (Suppl) 1987, 715: 157-163.

24. Scott, D.G. \& Bacon, P.A. Intravenous cyclophosphamide plus methylprednisolone in treatment of systemic rheumatoid vasculitis. Am J Med 1984, 76: 377-384.

25. Guillevin, L.O., Jarrouse, B., Lok, C. et al. Long term follow-up after treatment of polyarteritis nodosa and Churg-Strauss angiitis, with comparison of steroids, plasma exchange and cyclophosphamide to steroids and plasma exchange. A prospective randomised trial of 71 patients. $J$ Rheumatol 1991, 18: 567-574.

26. Conn, D.L. Role of cyclophosphamide in treatment of polyarteritis nodosa (Editorial). J Rheumatol 1991, 18: $567-574$. 